Presented at the 1992 Intl. Conference on

Electrostatic Accelerators \& Associated

BNL -48571

Boosters, Legnaro, Italy - June 1992

\title{
Design and Test of a Superconducting RFQ for Heavy Ions*
}

I. Ben-Zvi(a), A. Jain(b), J.W. Noé, P. Paul and H. Wang(b)

Physics Department, SUNY at Stony Brook, NY 11794-3800

A. Lombardi

INFN-LNL, Via Romea 4, Legnaro (PD) 1-35020, Italy

BNL- -48571

DE93 010862

\begin{abstract}
A prototype SRFQ resonator optimized for a velocity of $\beta=0.03$ and a charge to mass ratio $(q M)$ of $1 / 6$ has been designed, fabricated and tested. This is a short RFQ structure (only $2 \beta \lambda$ long) operating at $57.4 \mathrm{MHz}$. The resonator is made of copper, and a $1.5 \mu \mathrm{m}$ thick layer of electroplated $\mathrm{Pb}-2 \mathrm{at} . \% \mathrm{Sn}$ is used as the superconductor. The electrical characteristics of the resonator derived from detailed 3-D numerical simulations using the MAFIA codes, and also from measurements on the actual resonator are described. The multipactoring levels could be processed away with ease. Quality factor $(Q)>1 \times 10^{8}$ is obtained for $E_{a}$ up to $1 \mathrm{MV} / \mathrm{m}$. Other parameters relevant to superconducting operation are also presented.
\end{abstract}

\section{Introduction}

The Radio Frequency Quadrupole (RFQ) combines acceleration and focussing in one element, and is therefore very suitable for acceleration of low velocity ions. A normal conducting RFQ resonator, however, requires a high RF power. This makes a cw operation quite difficult. A superconducting RFQ (SRFQ) resonator could combine the advantages of the RFQ for slow ions with the cw operation and efficiency of superconducting linac structures. The design principles and possible application of the SRFQ as a linac injector were explored recently[1]. This paper briefly describes the design principles, and results of numerical and experimental studies of the characteristics of a prototype SRFQ resonator.

\section{Resonator Design}

The basic guidelines for our design were the use of the simple, low cost technology of lead (or lead-tin) plated on copper, the acceleration of very heavy ions (such as lead) with a charge to mass ratio ( $q M$ ) of $1 / 6$ or better and the concept of the RFQlet, a short RFQ resonator. Unlike a conventional RFQ, a RFQlet is designed to accept a pre-bunched beam. It combines the advantages of RFQ focussing with a wide transit time factor curve, low stored energy, small size and flexibility of the independently-phased resonator

*This work was performed under the auspices of the U.S. Dept. of Energy.

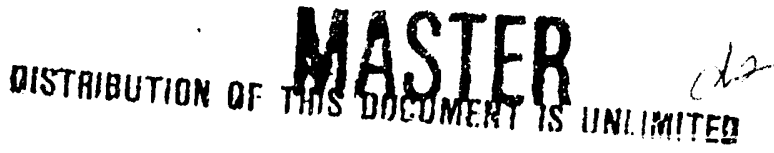


the numerically calculated fields is shown by the crosses. The good agreement with the measurements is evident. The peaks on both ends are due to the fringe fields, which make a non-negligible contribution to the total acceleration. The progressive decrease in the peak fields of the cells is a result of increase in cell length as the beam accelerates along the structure. The bead perturbation shows a noticeable magnetic field at about $\pm 0.1 \mathrm{~m}$ from the center (see Fig.2). This is perhaps due to the proximity to the inductive support tubes. The transit time curve calculated from the measured field profile peaks at $\beta=0.033$ and acceleration in excess of $80 \%$ of the peak can be obtained for $0.029 \leq \beta \leq 0.040$. The stored energy was calculated as $0.965 \mathrm{~J}$ at $1 \mathrm{MV} / \mathrm{m}$ acceleration field $\left(E_{a}\right)$, defined as energy gain per unit charge divided by the total external length $(58.5 \mathrm{~cm})$ of the resonator.

\section{Pb Plating and Superconducting Tests}

A $1.5 \mu \mathrm{m}$ thick layer of electroplated $\mathrm{Pb}-2 \mathrm{at} . \% \mathrm{Sn}$ is used as the superconductor. The resonator can, with an extension collar, was used as the vessel containing the electrolyte. Two L-shaped $\mathrm{Pb}$ sheets, and two 1.5 inch diameter hollow $\mathrm{Pb}$ pipes were used as anodes. A low current density of $-0.25 \mathrm{~mA} / \mathrm{cm}^{2}$ was used to avoid any whiskers. Due to the large surface area involved $\left(-19300 \mathrm{~cm}^{2}\right)$, the entire operation was carried out in an inert atmosphere of dry nitrogen.

In the room temperature RF tests after the plating, several very low field multipactoring levels were seen. The lowest, and the most stubborn level was at $E_{\alpha}=0.94 \mathrm{KV} / \mathrm{m}$, and corresponded to an inter-electrode gap of $1.5 \mathrm{~cm}$, consistent with the minimum aperture. All the levels could be cleaned with RF processing (maximum of $1.5 \mathrm{KW}$ peak/150W average RF power) in about 48 hours. Some higher levels $\left(E_{a}=60\right.$ and $80 \mathrm{KV} / \mathrm{m}$ ) showed up at $\mathrm{LHe}$ temperature, but could be quickly processed away. Multipactoring therefore is not a serious problem even with the complex geometry of this resonator. This is a very significant result from the point of view of practical operation of a SRFQ.

Mechanical stability of the resonator is an important requirement for superconducting operation. The resonant frequency excursions due to vibrations was measured to be $-60 \mathrm{~Hz}$ (peak-to-peak) with considerable disturbance coming from a rather noisy mechanical pump. The frequency excursions reduced to $\sim 20 \mathrm{~Hz}$ with the pump isolated. These stability figures are reasonable, though not as good as the best linac structures. In principle, the structure could be improved by dampening the mechanical $Q$. The resonant frequency variation due to the LHe pressure change is $160 \mathrm{~Hz} / \mathrm{psi}$.

The $Q$ as a function of $E_{a}$ was measured in a standard fashion using a phase locked loop and critical coupling. The resulting curve is shown in Fig.3. The low field $Q$ is $1.5 \times 10^{8}$ and remains above $1 \times 10^{8}$ up to $E_{a}=1 \mathrm{MV} / \mathrm{m}$, achieved with only $3 \mathrm{~W}$ of $\mathrm{RF}$ power. It begins to drop sharply after this (circles in Fig.3). Considerable improvement was made by helium conditioning (squares in Fig. 3). Processing with a high power RF 


\title{
References
}

* Work Supported in part by NSF Grant No. PHY-8902923.

(a) Also NSLS Department, Brookhaven National Laboratory, Upton, NY 11973.

(b) Now at Brookhaven National Laboratory, Upton,NY 11973.

[1] I. Ben-Zvi, A. Lombardi and P. Paul, Part. Accel. 35(1991) 177.

[2] A. Schempp, M. Ferch and H. Klein, Proc. 1987 Part. Accel. Conf., IEEE Trans. Nucl. Sci. 87CH2387, 267(1987).

[3] A. Jain, I. Ben-Zvi, P. Paul, H. Wang and A. Lombardi, Proc. 1991 Part. Accel. Conf., IEEE Conf. Record 91CH3038-7, 2444.

[4] I. Ben-Zvi, A. Jain, H. Wang and A. Lombardi, Proc. 1990 LINAC Conf., September 10-14, 1990, Albuquerque, New Mexico, p.73.

[5] H. Wang, I. Ben-Zvi, A. Jain, P. Paul and A. Lombardi, in reference [3], p.3038

\section{DISCLAIMER}

\begin{abstract}
This report was prepared as an account of work sponsored by an agency of the United States Government. Neither the United States Government nor any agency thereof, nor any of their employees, makes any warranty, express or implied, or assumes any legal liability or responsibility for the accuracy, completeness, or usefulness of any information, apparatus, product, or process disclosed, or represents that its use would not infringe privately owned rights. Reference herein to any specific commercial product, process, or service by trade name, trademark, manufacturer, or otherwise does not necessarily constitute or imply its endorsement, recommendation, or favoring by the United States Government or any agency thereof. The views and opinions of authors expressed herein do not necessarily state or reflect those of the United States Government or any agency thereof.
\end{abstract}




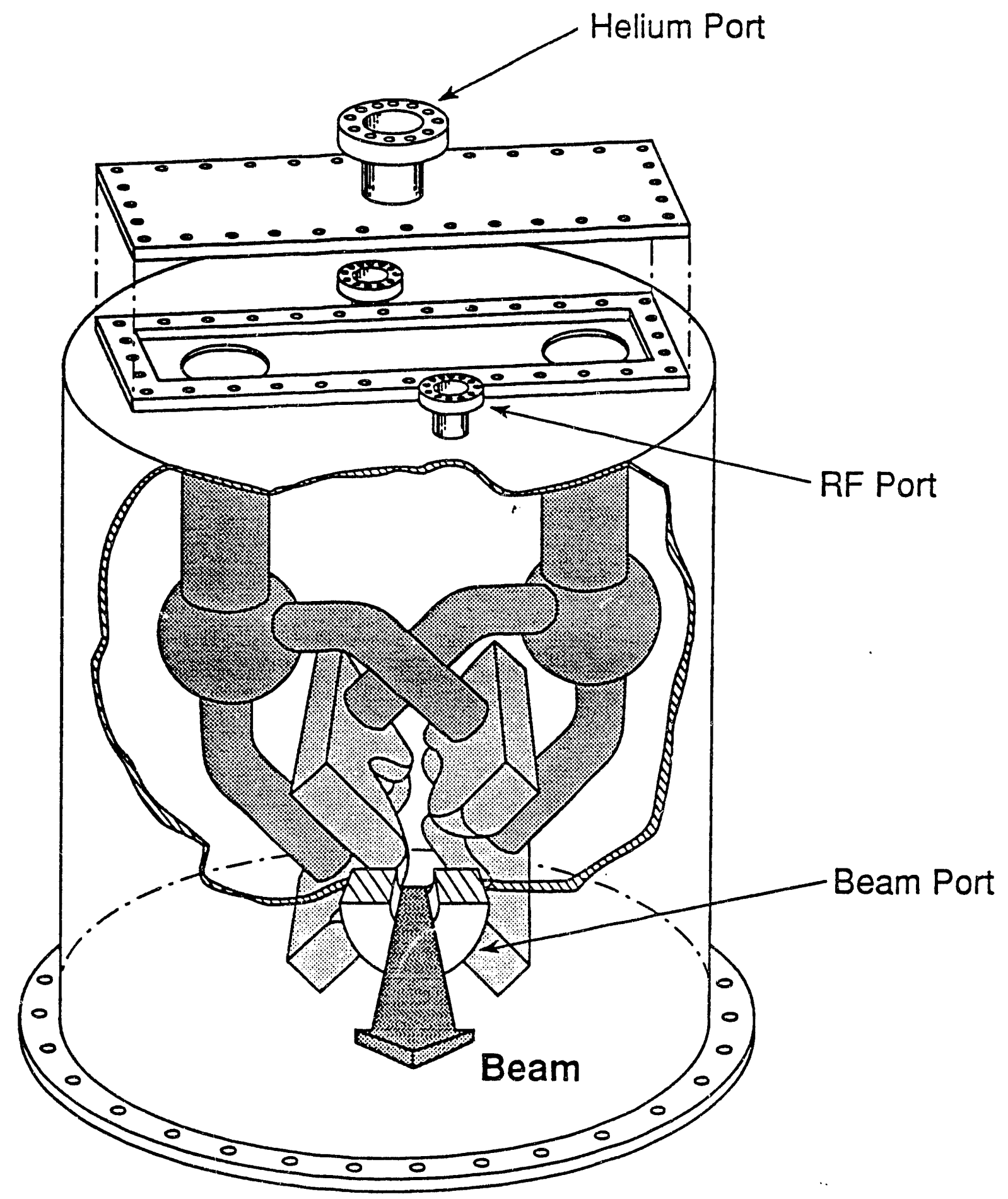

Fig. 1 


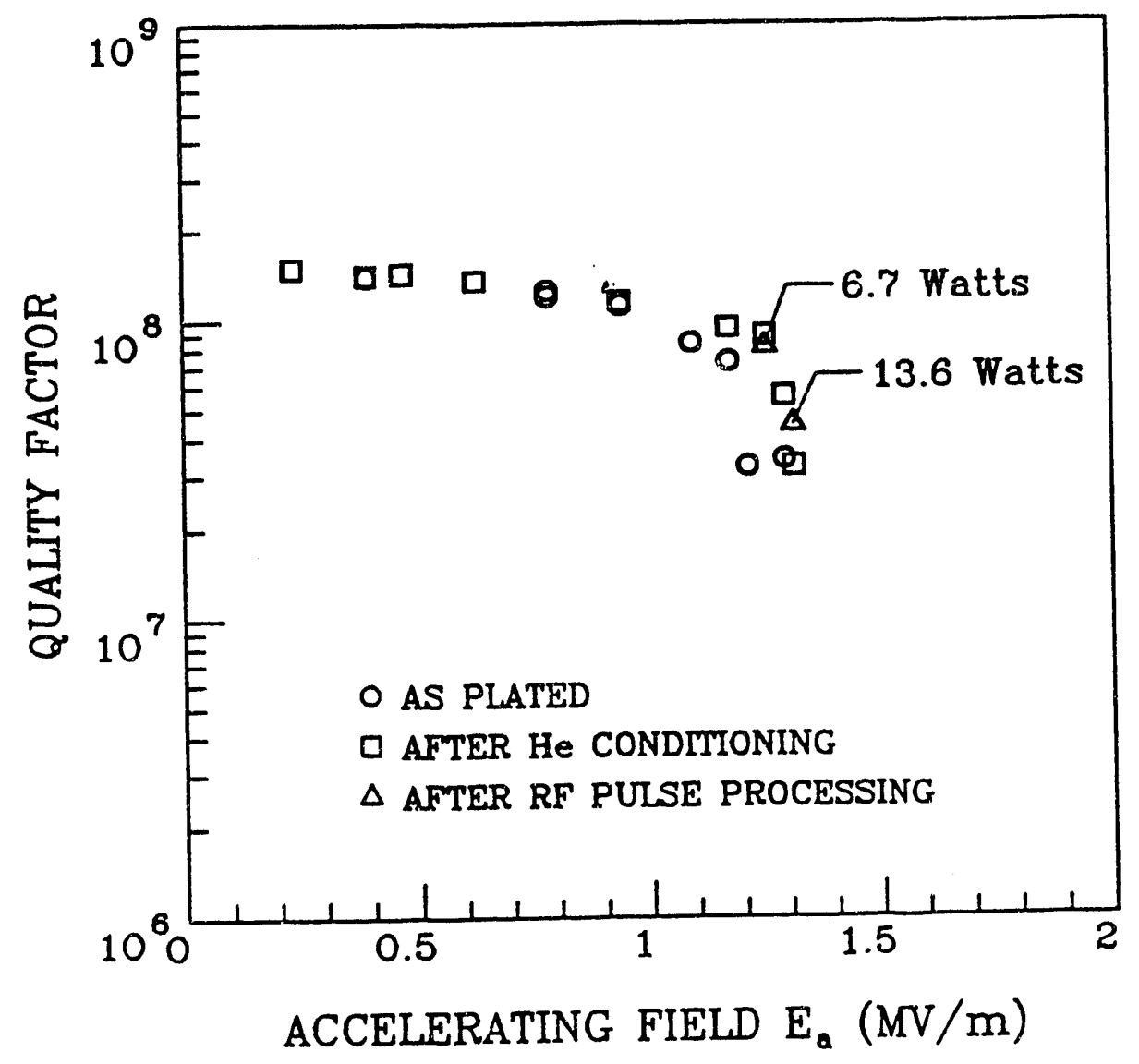

Fig.3 



| 
